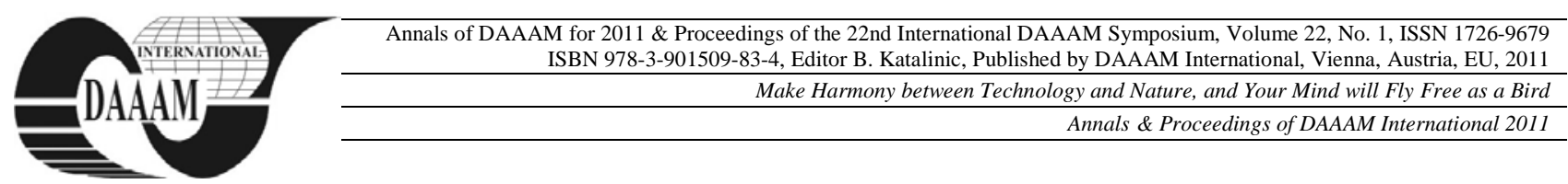

\title{
TRANSFORMER INSULATION - MODIFICATIONS IN LIQUID PART
}

\author{
TRNKA, P[avel]; PIHERA, J[osef]; POLANSKY, R[adek]; PROSR, P[avel] \& MENTLIK, V[aclav]
}

\begin{abstract}
Power or distribution transformer is a reliable high performance electrical machine transmitting high power using high voltage technology. The reliability of a power transformer is directly linked with its electrical insulation reliability. Electrical insulation of large machines is based on paper-oil insulating system. Due to the international agreements and environmental requirements it is compulsion to substitute petroleum-based oils with synthetic esters or vegetable fluids with good electrical properties as well as with proper features connected with biodegradability. This topic is the main problem of presented paper. This paper connecting outlines of several papers already published by authors and presenting the current state in the observed field of interest.

Key words: electrical insulation material, dielectric fluid, new insulating mixtures, biodegradability, synthetic oil, petroleumbased fluid
\end{abstract}

\section{INTRODUCTION}

Liquid element of the electrical insulation system of a transformer plays important role in creating its final properties. Liquid element limits the transformer electrical insulation parameters, dissipated heat transfer capabilities and machine livingness. In general, transformer insulation consists of insulating fluid - oil and cellulosic paper. Petroleum based insulating fluids are used as a liquid element of for example transformer insulation system or $\mathrm{HV}$ cables (Mladenovich 2010). Transformer insulating system is subjected to variety of stresses over the machine operation. Under the influence of the operation stresses, presents of oxygen and moisture, the insulation system deteriorates continuously over period of time. At the present time a special concern is given mainly to the application of insulating liquids considered to inflict minimal harm on the environment. This paper present current state of the problematic of possible substitution of the petroleum based insulating fluids. Problems appearing during petroleum based liquids substitution are presented and studied.

In following text is presented a short description of the different insulating liquids and the process of their manufacturing.

\subsection{Petroleum-based Insulating Fluids}

Petroleum-based oils (mineral oils) are multi-component hydrocarbon mixtures of the specific boiling range. They were in use as liquid dielectrics in electrical equipment for over hundred years now. Oil used for insulation in transformers is obtained by refining crude petroleum. Refining involves two major branches; separation processes and conversion processes. There are many processes available to the refiner and the final processes chosen is determined by the products required (both quantity and quality) and the crude oil available. Over time changes to either product requirements or available crude oil can result in changes to the refining processes necessary in the refinery. There are many types of crude oil which come from diverse sources around the globe. Selection of the crude oil is a key part of the refining process. Selection of the source to process depends on many factors including; quality, availability, volume, political banks and price. The first stage of crude processing is distillation. This process takes place in a column known as a Distillation Column. In the process of distillation is crude oil (a mixture of hydrocarbons) boiled and recondensed to separate the crude oil into components based on ranges of boiling points. Heavy and harder to boil components will collect in the bottom part of the column. Lighter components have lower boiling points so it can be collected at the higher parts of the column. To the upper part of the column coming stream of gases known as LPG (Liquefied Petroleum Gas). Now some components undergo further processing for example hydroprocessing. The objective of the process is to remove sulphur. The hydrogen is used to help in the sulphur elimination. This is important nowadays when problem with corrosive sulphur in transformer is observed.

The finishing phase of the refining process is blending. This is a crucial step where the various hydrocarbon components manufactured in the refinery are mixed together to make the products with required properties - in our case transformer oil. Sometimes are substances obtained by this process even considered as synthetic, but still petroleum-based.

Despite the availability of a variety of synthetic oils and progress in natural esters research, petroleum-based oils held its way, due to their availability, economy and satisfactory dielectric properties.

\subsection{Synthetic Oils}

Similar internal structures as petroleum-based oils have synthetic esters. Synthetic esters contains of poly-functional alcohols. Esters often don't rectificate purposely after the synthesis to preserve the products variability. Technical requirements imposed on these oils have to respect differences in their chemical composition. Ester with similar electric insulating properties differs in other characteristics Ferrari (2005).

Synthetic ester oil is mixture of chemical compounds which are not originally present in crude petroleum. There are more possibilities of preparing synthetic ester. One of them is using the Fischer-Tropsch process which converts carbon dioxide $\left(\mathrm{CO}_{2}\right)$, carbon monoxide $(\mathrm{CO})$, and methane $\left(\mathrm{CH}_{4}\right)$ into liquid hydrocarbons of various forms. This process was developed and used extensively in World War II. A different procedure of synthesis of ester is based on removing highly viscous bitumen from oil sands and using a variety of processes of hydrogenation to turn it into high-quality synthetic crude oil. This process is used in Alberta, Canada.

The disadvantage of many synthetic oils is initial costs usually two to four times greater than petroleum-based oils. Other problems are with their potential decomposition in definite chemical environments.

The future of synthetic ester in the terms of renewable technologies can be in the new accesses of ester synthesis. According to research of Lamsa (2008) synthetic ester can also be obtained from a vegetable oil using two stage transesterification. 


\subsection{Natural-based Oils}

Natural oils are notably simpler group of substances with similar chemical composition and high boiling nature. Chemically similar, both synthetic and natural ester oils are made by a combination of organic acids and alcohols. They can contain triglyceride (formed from a single molecule of glycerol, combined with three fatty acids on each of the $\mathrm{OH}$ groups) consisting of a mixture of saturated and unsaturated fatty acids. Saturated fatty acids contain no double bonds between the carbon atoms of the fatty acid chain. They are thus saturated with hydrogen atoms. Fatty acid is a carboxylic acid which is either saturated or unsaturated. Most of the fatty acid consists of the unsaturated type, which consequences low viscosity and better low-temperature properties.

Opinions on using natural ester in the power transformers differ. Many transformer manufacturers decline any effort of substitution of mineral or synthetic oil, some promoting opposite.

Some opposite opinions found in literature:

"Animal oils and vegetable oils are not used for the purpose of forming fatty acids on heating which are corrosive for the cellulosic paper used in insulation” Verma (2005).

However, some papers deals with the results of testing natural esters in medium power transformers with success:

"Natural esters fluids can be applied to medium power transformers up to at least $450 \mathrm{kV}$ BIL utilizing insulation systems designed for conventional mineral oil.” Smith (2006).

As was said before vegetable oil is mainly mixture of triglyceride esters of fatty acids, a few but various lipoids, and free fatty acids. Crude vegetable oils extracted from oil seeds, have a dark color and contain solid constituents such as proteins and fibers. For example rapeseed oil contains of the primary fatty acids (oleic $\mathrm{C}_{18} \mathrm{H}_{34} \mathrm{O}_{2}$ and linoleic $\mathrm{C}_{18} \mathrm{H}_{32} \mathrm{O}_{2}$ ). In order to use this type of natural oil in a transformer, the acid value has to be lowered using refinement. In $\mathrm{Li}$ (2006) a three step procedure to improve the oil properties was used: alkaline refinement, bleaching and decompress distillation.

\subsection{New Insulating Mixtures}

In order to obtain relatively stable insulating fluid with proper electrical properties and other features as viscosity and flammability - new mixture fluids are being developed. This fluids will represent their good properties such as high flash point - synthetic or organic based fluids, stability and low viscosity - petroleum based oils and partial biodegradability based on the percentage of biodegradable compound in the mixture.

\section{TESTING}

Till now - three groups of insulating oils were subjected to the long time aging tests. In addition some other paper-oil systems are being tested.

It is expected different influence of tested oils on paper-oil insulating system. Therefore the investigation is focused on the identification of oil (insulating liquid) influence on final properties of a transformer insulating system. Obtained results help us to search for a suitable substitute for the petroleumbased oils. Differences between fluids can be seen e.g. on viscosity, Table 1.

The aging test was performed on the temperature of $90^{\circ} \mathrm{C}$. In the pre-defined time periods were measured electrical parameters. Recorded were parameters time dependencies.

Next test is performed for three different temperatures of 100,110 and $120^{\circ} \mathrm{C}$ in order to obtain the life time curve.

\begin{tabular}{|l|l|}
\hline Tested Insulating Fluid & $\begin{array}{l}\text { Viscosity } \\
{\left[\mathrm{mm}^{2} / \mathrm{s}\right]}\end{array}$ \\
\hline Shell Diala DX & 8,68 \\
\hline Technol Y 3000 & 8,40 \\
\hline Cooper FR 3 & 33,9 \\
\hline Rape-seed oil & 34,94 \\
\hline Sunflower-seed oil & 31,59 \\
\hline Di-2-ethylhexyl ftalát & 27,4 \\
\hline Di-2-ethylhexyl adipát & 7,82 \\
\hline Radiolube & 46,83 \\
\hline Priolube & 44,34 \\
\hline Zerol Ester 22 & 19,2 \\
\hline
\end{tabular}

Tab. 1. Differences in viscosity of electroinsulating fluids for use in power transformer

\section{PROJECT DELIVERABLES}

Problematic of research in the field of insulating fluids is actually being solved. Especially countries with limited access to petroleum are conserning substitution of the petroleum-based fluids. Also the environmental problems of petroleum are more and more concerned.

With effort to use of environmentaly friendly materials in industry are connected problems with different parameters of new materials. New developed and designed electrical appliances can be built with a new material. In the case of repleacing of the material in the current appliances it is neccessery to know exactly all material parameters. In the case of insulating liquids it means breakdown voltage, dissipation factor, resistivity, viscosity, flammability, biodegradability, capacity, specific heat capacity, permittivity, water content, etc. The most important is livigness of such as fluid in the transformer working condition. For such as use we need to redesign the properties of the fluid in such as way to fulfill all technical specifications.

\section{ACKNOWLEDGEMENTS}

This study was carried out with the support of the Ministry of Education, Youth and Sports of Czech Republic, MSM 4977751310 - Diagnostic of Interactive Processes in Electrical Engineering.

\section{REFERENCES}

Smith, S. D. (2006). Design and Test Experience With Natural Ester Fluid for Power Transformers, Proceedings of T\&D Conference and Exposition, Dallas, Texas, IEEE PES, ISBN 0-7803-9194-2, IEEE, Dallas

Li, X.; Li, J. \& Sun, C. (2006). Properties of Transgenic Rapeseed Oil Based Dielectric Liquid, Proceedings IEEE SouthEastCon, IEEE SouthEastCon, IEEE, Memphis, TN.

Verma, P. (2005). Condition Monitoring of Transformer Oil and Paper, [Disertation Thesis], Deemed University, India

Ferrari, R.; da Silva Oliveira, V. \& Scabio, A. (2005). Oxidative stability of biodiesel from soybean oil fatty acid ethyl esters, Scientia Agricola, Vol. 62, no. 3, May/June 2005, Piracicaba, Brazil, pp. 291-295

Lamsa, M. (2008) (Raision Tehtaat Oy AB, FIN-21200 Raisio, Finland) PCT International Patent, Application WO $96107632 \mathrm{Al}$

Mladenovic, I. \& Weindl, Ch. (2010). Influence of the Thermal Stress on the Diagnostic Parameters of PILC Cables, Proceedings of the 2010 International Conferennce on Condition Monitoring and Diagnosis, Tokyo, Japan, ISBM 978-4-88686-070-5, IEEJ, IEEE, Tokyo 